\title{
Impact of Scrum and Tactic Workflow Management System on Organization Performance (A Study on Animation Studios in Pakistan)
}

\author{
Abdul Wahab Khan ${ }^{1}$, Usman Khan ${ }^{2}$ \\ Maaz Bin Ahmad ${ }^{3}$ \\ College of Computing and Information Sciences \\ PAF- Karachi Institute of Economics and Technology \\ Karachi, Pakistan
}

\author{
Farhan Shafique $^{4}$ \\ Dept. of Computer Science \\ FUUAST \\ Karachi, Pakistan
}

\begin{abstract}
Assessing and considering the efficiency effect of scrum management system is a significant and troublesome issue for a researcher. We prescribe that you best comprehend the adequacy of scrum management system applications by breaking down at the data handling level in the animation studio. As we going to concentrate on the progression of data with others in the association procedure is moderately not coupled, to oblige the estimation issue. In light of the aftereffects of this research, it will reason that in the wake of actualizing the scrum management system framework, the organization will turn out to be progressively proficient and compelling underway exercises. Also, its exhibition will upgrade and the greater part of the issues will resolve effectively which prompted better profitability and a superior notoriety in the market. The study additionally attempted to underline the effect of animation studio the scrum management system. It is proposed to determine how the scrum management system causes a movement studio to work adequately. Research proposes that activity studios ought to give adaptability to execute the executives data frameworks, ought to likewise be noticed that to advance control of the organization's market and obtain sufficient programming and a proper program through correspondence media associations to meet the worldwide scrum management system business condition in the developing business sector development and extension.
\end{abstract}

Keywords-MIS (Management Information System); scrum management system; deployment; performance; animated studios

\section{INTRODUCTION}

The universe of Information System (IS) in associations gives various cases of fruitful IS execution that gives advantages to the two business and representatives working for them. These advantages incorporate better gainfulness and better performance of a complete organization [8] [12] [15]. This is also true for effective business processes or individuallevel work routes [6] [10] [13].

Based on resource-based view (RBV) theory, a few scholastics recommend that interior business procedures could be essential factors that connect IT capacity and organizational performance [7] [15]. IT capabilities, although it is considered a key asset [21] Can't make an incentive in a vacuum, its part in supporting vital business forms is impacted by extraordinary effects [1] [18] Academics also say that such unusual effects are important for the implementation of IT capabilities, in which conditions are to be changed by changing conditions [15], [17]. In the present period Business administrators are unmistakably progressively included about the impact of rivalry as contrast with a couple of years back. They ought to need to react to restricting dangers not only from local sources yet territorial as well, national and worldwide sources; they have likewise attempted to locate every single accessible open door in the national and worldwide condition in a split second. Deregulation has expanded focused weight for associations, endurance, and flourishing.

The scrum management system likewise ascertains the side idea of data stream and Configuration of associations around the choice focuses. Execution benchmarks are a piece of any great arrangement as well. For reasons unknown, Depending on the accessibility of the pertinent administration data framework as deciding quality as different parts of the arranging procedure.

\section{A. Background}

Scrum management system has a significant job in rivalry among organizations. Organizational capacities, for example, the general fitness of an organization to orchestrate its composite HR and different assets adequately to accomplish corporate execution [11]. Organizations can get a contending predominance by picking up or developing authoritative capacities that are commendable, extraordinary, can't be copied in a perfect world and are not commutable in uncommon mixes. Given that the capacities of the association slope to show course confirmation, arbitrary vulnerability, and social trouble, a contention advantage created by size can be continued for more term of time [16] [20].

Limit of IT has been portrayed as the capability to prepare and execute assets of IT mixture with different assets and capacities of the association [4]. Under resource-based view (RBV) IT abilities that displays the features of interesting attributes, Appropriability, non-reproducible, and nonsubstitutability, could be a wellspring of driving act [18]. Data System researchers have altogether tried the impact of IT limit 
on the exhibition of the organization. Organizations that has more IT limit slanted to exceed rivals in a scope of execution gauges dependent on points of interest and costs [4]. Besides, there is expanding confirmation that contention benefits often depend on either organization to make the limit of their IT limit [5].

In animation studios, there are numerous offices and each division works like a column, they ought to have legitimate data so they can settle on a choice on schedule and perform better. Scrum management system will assist them with making better choices and perform well by giving them appropriate data on schedule.

\section{B. History of Waadi Animation}

Waadi Animations began in 2014 with ten visual specialists and twenty PCs. Of the twenty frameworks, ten were utilized as rendering hubs, while the rest were distributed as workstations for the illustrators, special visualizations, craftsmanship and sound. They utilized i7 Intel processors, with $16 \mathrm{~GB}$ frameworks and $2 \mathrm{~GB}$ realistic cards. To spare costs, they changed over a framework into a server. Later when they started building up their whole activity, they fabricated servers and made hubs as the group developed.

The principal film took eighteen months to finish and in spite of the fact that the last item was a first of its sort in Pakistan, it was of disappointing quality. The underlying driver of this was related with fumble of time and misallocation of assets. Cutoff times were not met and assignments were not being concluded. Basic choices couldn't be made in light of the fact that tests couldn't be audited in time which further postponed the criticism procedure. Issues and protests couldn't be settled in due time and would consider antagonistically the group's presentation. The procedure was Adhoc and being a beginner group, they learned by committing errors as they went.

Another issue that was confronted was the utilization of appropriate innovation. Having no earlier information or experience with respect to what PC frameworks would have the option to hold up under the heaviness of prepared livelinesss. At first, the procedure was run on CPU-based rendering. CPU-based renders would mean a casing would be delivered each hour. As they advanced and with the headway in innovation, they moved to GPU-based rendering which was quicker and practical. Presently, each edge could be delivered in a short time. This implied procedures and undertakings that used to take a year, could now be finished in four months.

\section{Implementation}

The team is divided into Art, Composite, Modeling, Animation, VFX, Lighting and Render, all in constant liaison with the IT team. The process is broken down into fortnightly sprints. The process of decision making begins with calling team meetings.In those meetings, every member is debriefed on their daily workload. - SCRUM Methodology in the supervision of Head of department and Lighting Supervisor. This can take place between the heads of each department where strategies are outlined for how a script will be processed into an animated film. The goals of each sprint are finalized and then, these are delivered to each department. Each member gives brief answers to three essential questions:

1) What I completed yesterday?

2) What I aim to complete today?

3) What obstacles I face in completing my tasks?

Some departments run independent of one another and do not need to wait upon others to complete allotted tasks.

In those instances, the team leader will decide to pull upcoming deadlines closer to reduce lag and direct attention towards secondary tasks.Although this keeps labor costs low, it is inefficient as later on, it can become burdensome on the team as they have to do overtime to catch up on missed deadlines. But, with the use of the software, we can track the progress of each team member.

As each task is being worked on, the software allows team leaders to assign small, realistic goals within realistic deadlines and then tracks the time spent by each team member in completing it. With accurate up to date information about what percentage of the workload has been completed, team leaders can make decisions about how to plan for the coming fortnights.

\section{Research Problem}

Information technology is widely viewed as a key reason for the growth of any business [5]. Information is very important and also describe the cable of any company (public limited business, private limited companies, local business, multi-national industries, franchising, retail outlets, and chains). This guides you into more intelligent way and enables the right job to be completed at the right time [22].

Expert of information system discussed that companies must build the good information system to accomplish companies goals [17] [4] In essence, the concept of IT capacity underlines IT resources are shared resources, together with the importance of mobilization and deployment, and other resources and capabilities [4].

\section{a) Research Questions}

- RQ1: Does the deployment of scrum management system has an impact on organizational performance?

\section{b) Research Objectives}

- RO1: To study the impact of deployment of scrum management system over organizational performance.

c) Hypothesis

- H1: Deployment of scrum management system positively impacts on organizational performance.

\section{E. Contribution of Study}

The Animation studio sector goes around different issues and challenges, which impact on the organizational performance directly. We see much lacking in the animation studio system; related to administration, production activities, project planning, project deadlines, and communication issues, etc. There is literature available that talks about different 
aspects of organizational performance. Different researches has done primarily on scrum management system in business sectors, hospitals, and education sectors but we did not find any research related to scrum management system deployment in Animation Studios in Pakistan.

It is therefore believed that this research will provide solid groundings to work over this main sector as well specifically in developing countries. Currently, this study caters only two variables i.e. deployment of scrum management system as an independent variable while Organizational Performance (animation studios) as a dependent variable due to limitation of time. But this will provide a road map for others to follow this gap after this research.

The study under consideration variable and it impacts, it is aimed to come with logical groundings to present statistical data to top management, enforce them to take reality base actions in animation studios in Pakistan for the organizational performance.

\section{F. Scope and Limitation of the Study}

Animation Industry is an extremely huge industry and furthermore called the cash multiplier industry. This specific examination will concentrate on the Animation Studios of Pakistan. The absolute populace is the staff working in Animations Studios in Pakistan, incorporates creation and non-generation (administrative and managerial) staff. The constraint of the examination is that we have not many activity studios in Pakistan. The complete number of animation studios of Pakistan is 10 with around 1000 creation and around 200 non-generation staff. The assortment of information will be done through a survey and from creation staff just cooking the both gender orientations staff on an accommodation examining premise. The present investigation has one autonomous variable. Scrum management system Deployment in Animation Studio. While one ward variable as the authoritative execution of movement studios. Numerous components influence authoritative exhibition. In any case, this examination is concentrating just on one variable that is thought to be very solid for the liveliness business of Pakistan. The extent of this investigation won't be constrained to this exploration, yet it could be conveyed forward with a similar variable on different areas of Asia and the remainder of the world.

\section{LITERATURE REVIEW}

Scrum management system indicates that communication is a must for the performance of the organization and management functions linked to the external environment. The scrum management system set a link to communication, making activities and responsibilities possible for administration and managers.

Concern over scrum management system and improved handling result in reduced bottlenecks associated with management processes. The managers were reorganized for years, so the traditional production information for the performance has had limited control value. However, In many companies, this is the only type of data that is regularly collected and analyzed. Management needs a variety of product information regarding the external environment, such as electricity, cooling systems and technology development.

The scrum management system is a functional system to collect, compare, analyze and distribute external and internal information to the company in a very efficient and effective way [19]. The scrum management system can be defined as supporting the executive branch to provide a competitive advantage that must support the organization's goals [14] [9]. Explains that scrum management system works as a planning system for collecting, processing, storage and transmission functions needed to manage the data format information provided.

The scrum management system uses formal strategies to provide appropriate information to all levels of management based on external and internal data and helps them to arrange coordinate and control the auspicious and powerful choices of the exercises they participate in.

An efficient scrum management system framework regularly utilizes PC and other sophisticated technology to process data that mirrors the everyday activities of the organization. In light of the above, scrum management system framework is a coordinated manual PC framework that gives information to help the tasks of administrations and the decision making elements of an organization. Scrum management system framework is additionally an accumulation of individuals, strategies and gadgets sorted out to change over data from interior and outside sources into information and impart such information in a proper frame to administration and management by any means levels.

The scrum management system framework additionally incorporates the association of people, procedures, and contraptions to change over information from inside and outside information sources into data and convey this data in any capacity to the executives and the board in a fitting structure.

A proficient scrum management systemprocess information that mirrors the association's every day exercises by utilizing PCs and other refined advancements. Considering this, scrum management systemis a planned framework structure that gives assistance as far as data to settle on better basic leadership exercises in an association. The scrum management systemstructure likewise incorporates the association of people. Contraptions and procedures to change over information from outer and inner information sources into data and impart this data to organization and the board using any and all means levels.

\section{A. The Software}

The software used in the animation industry to manage projects and production tracking simultaneously is called SouthPaw TACTIC. It is a LINUX-based open source software which can be installed on a server and is accessible via both Windows and Mac systems. An operator can connect to it via a T-SQL database that records all employee access information and allow specific permissions to each user i.e. rights for file generation, modification and sharing. TACTIC works through the database which sits on a server, with a 
portal front end. A user enters their designated username and password, can view their daily progress. All files they have worked on will be accessible via the portal. Because everything is connected via a centralized system, all complaints and issues can be immediately resolved, performance indicators can be measured and allow greater control over projects which further helps team leaders plan and strategize for the future.

Through TACTIC, the team leaders can assign specific tasks to entire teams by grouping users and placing deadlines on the teams. Alerts are systematically sent out to team leaders and members as deadlines approach. But apart from the production, the software also links this data with other departments such as Administration, Project Management, Human Resources, Marketing, Accounts and IT.

\section{B. Tactic}

In the event that something is completing, there must be a work process included. Strategy work process is a work process motor planned around the conviction that each organization, regardless of whether they know it or not, is utilizing work process to do what they do.

In the event that a chief plunks down with a pen and a napkin, they ought to have the option to draw the work process they see around them consistently. In numerous organizations, the manner in which procedures and systems are done is a successful and full grown procedure. As a rule, off-the-rack the executives programming's demands their bearing of sorting out work processes, tossing out what is natural and generally effective. What we are keen on is taking what as of now exists in an organization and carrying it to a more elevated level of ability.

Strategy work process isn't intended to upset; it is intended to incorporate and improve work process pipelines. It utilizes these pipelines to outwardly speak to the inward procedures of an organization, enabling upper administration to put and allocate needs and observing how it will influence the whole work process, continuously. As a pipeline is fabricated, code is being created out of sight that brings ground-breaking computerization at a director's fingertips. We realize that a work process isn't simply from A to B. The TACTIC pipeline underpins the intricacy that can be normal in a genuine workplace through computerized procedures and choice trees.

Everything that occurs in an undertaking is followed through errands, notes, and resources. Strategy work process handles this data through a perplexing information framework and presents this information through Views custom-made to various client types. This joined with an adjustable notice framework guarantees that everybody is seeing the correct data. Strategy tracks computerized resources through the creation procedure progressively, changing information into accessible resources as you work. It robotizes the naming, arranging, following and looking through computerized resources, making work process association quick and programmed. Along these lines, the work process motor guarantees that conveyance is constantly smooth and that records never get lost or disappear. TACTIC workflow is webbased and is accessible from anywhere with an internet connection. When a workflow is hosted in an effective web solution, significant obstacles are overcome in the area of remote people and teams. Two people from across an ocean find themselves using the same ways to work and communicate as two people in the same room. TACTIC Workflow brings automated work processes such as validation, triggers and decision trees with human project management together under a single workflow engine. It steps into an existing or brand new work environment and looks to enable companies through the many tools it has to offer. The result of all of this is that people spend less time wondering what to do and more time doing what needs to be done.

The goal is to advocate the use of an scrum management system in film production in Pakistan to enhance performance and productivity while simultaneously cutting back on the amount of time production can take.

- Advantages of TACTIC

- Provides up to date statistics of the task at hand to all concerned team members.

- Monitoring of performance can be easily measured.

- Allocate and assign reasonable and visible deadlines.

- Can cut costs down by nearly $40 \%$ Regular issues.

- Connectivity issues: regular internet outages.

The software needs to be constantly connected to a secure, upgraded and customized LAN but connectivity issues due to low-quality hardware or power outages at the ISP can cause a breakdown in correspondence between nodes and team leaders

- Database administration costs

The server houses the entire database of employee records, script and animation render files. In order to actively maintain this vast collection of data, the system requires skilled IT labor, such as programmers, database administrators as well as systems engineers for the upkeep of the servers.

\section{Discussion of Variables}

a) Deployment of scrum management system: Scrum management systemmeets the diverse needs by querying the system, system analysis, system modeling, and decision support systems and other systems.

Scrum management system supports the control of management, strategic planning, operations and data flow control between departments. scrum management system assists animation production in distribution of animation tasks in forms of concept art, color keys, modeling, uv's, rigging, animation, light/shade/rendering, VFX and composite, the status of a particular scene or shot or an asset on a discrete level and reference to a variety of production related documents.

Scrum management systemguides Lead of every department namely modeling, animation, lighting, and VFX by providing them with the operational data they need for planning, scheduling and make their participation possible in decision-making at the operations level to control the project 
deadlines. Scrum management system assists supervisors to conduct short-term planning, goal setting, and production control. Planning and management control tools support it, respectively.

Scrum management system assists management at the highest level in goal setting, strategic planning and the evaluation of animation production plans and their implementation. The role of scrum management system is to generate information, make better communication, identify the problem and helps in the decision-making process. scrum management systemis a crucial part of the management, administration, and operations of an organization.

b) Organizational Performanc: scrum management systemhas a very crucial role in the organization; this will have an impact on the function, performance, and productivity of the organization. The impact of scrum management systemon the function under management support, scrum management system manages animation production tasks, schedule meetings and deadlines for tasks, and production control and personnel become more efficient. The monitoring of overall production becomes controllable. The production heads are kept alert by providing certain information for tracking the overall performance and project completion percentage. This results in predicting and controlling the timelines and taking necessary and important decisions when required. Reporting system based on the information provided by the Leads, Head of departments and supervisors helps in tracking, managing and controlling the tasks workflow and saving valuable time.

Scrum Management System in animation production helps the organization in understanding the life and complexity of the project. The scheduling of tasks for the production clearly shows the estimated timeline and approximate delivery time of the project. It helps in dealing with the potential bottlenecks of the projects, they can be in the form of artist's needs for the specific job or the technology barrier or can also be a hardware resource required to meet the need of the current project. Scrum management system require systematic business operations to achieve an effective system design. This prompts a stream of activities that muddle the outline of the framework. This enhances business administration by bringing discipline into their activities, as everybody must take after and utilize frameworks and techniques. This process gives a high level of professionalism in business operations.

Business goals and objectives are resulted by scrum management system goals and objectives. This aides in pushing the whole association one way toward goals and objectives, giving applicable data to the association and down the line to the working artist.

A well-designed system with an emphasis on the Lead and supervisor affects the effectiveness of management. The information foundation motivates an enlightened lead and supervisors to use various management tools. This helps them to resort to exercises such as experimentation. Using computers allows you to use tools and methods that you cannot use manually. Impact on management ability to perform. This greatly increases the effectiveness of decisionmaking.

Scrum management System in the animation production process plays a very important role and is considered to be a backbone for achieving the goals of the project. It's not just merely a system for managing tasks but a workflow of precision. The heavy paperwork of supervisors is transferred to a computerized system, making it easier for the human mind to work better. It should be noted that most of the workforce is involved in this activity in the organization. This Scrum management System has a direct impact on this cost.

\section{Hypothesis Development}

This study aims to target animation studios of Pakistan for studying the effect of understudy variables on the organizational performance of Animation Studios. Animation Studios Performance is considered as a dependent variable while one factor scrum management system deployment is considered as an independent variable; to study their impact on Animation Studios Performance.

Ho: Deployment of Scrum management System positively impacts on Organizational Performance of animation studios.

H1: Deployment of Scrum management System does not positively impacts on Organizational Performance of animation studios.

\section{E. Summary}

At current, animation industry of Pakistan faces different challenges that playing a major role in dissatisfaction with their production. This study will results over the impact of MID Deployment on Organizational Performance of animation industry of Pakistan.

\section{METHODOLOGY}

This research targets the animations industry of Pakistan for studying the effect of Scrum management System deployment on organizational performance. This section portrays the foundation to the study, factors linkages with hypothesis, strategies for gathering information, depicting programming that would be utilized for breaking down the information gathered, setting objective populace and test size, explore approach and structures of factual models. This part will lead this investigation towards the outcomes and talk stage.

\section{A. Conceptual Framework}

In this study, We have taken two variables; one is independent while the other is a dependent variable. I aimed to establish the link of an independent variable with the dependent variable Fig. 1.

\section{a) Independent Variable}

- Deployment of scrum management system.

Deployment of scrum management system is considered as an independent variable for my study. 




Fig. 1. Conceptual Frame Work.

\section{b) Dependent Variable}

- Organizational Performance of Animation Studios

Organizational performance of animation studios concerning the deployment of scrum management system is considered as a dependent variable in my current study.

c) Data and sampling frame work: There is a total of ten animation studios currently working in Pakistan with around staff of 3,000 employed over there. Out of these 3,000 employees, around 2,500 is production staff while around 500 employees are Administrative, marketing, and other support departments. Data has been aimed to collect from three organizations and 52 employees are the sample size calculated from Rao soft calculator with $10 \%$ margin of error and confidence level $85 \%$ for this study. Data is collected through a self-administered questionnaire.

\section{B. Measurement of Variables}

The survey instrument which is used for data collecting is based on five-point Likert scale for Section 2, adopted as per previous literature and published studies. The scale of the study is set as Strongly agree $=5$, Agree $=4$, Neutral $=3$, Disagree $=2$ and Strongly disagree $=1$. There are four variables in this section of the instrument i.e. Promotional policies, employee empowerment, Working environment, and Employee satisfaction, each having four statements to inquire responses from the respondent. Refer Table I for a detailed description of instrument adaptation.

\section{Statistical Models and Analysis}

The aforementioned research will be using Correlation analysis for examining degree of association between variables. To study the impact of understudy independent variables on job satisfaction and to test the hypothesis set earlier in the study, this will be done through multiple regression analysis. Regression analysis is a statistical tool when to find the impact of one variable over the other To implement these models and perform descriptive analysis on the collected data, a statistical package for social sciences (SPSS) version 21 will be used.

\section{Diagnostic Analysis}

Before approaching to collect data through a survey instrument, pilot testing of the instrument has been done. Based on the sample size from the population i.e. $260,10 \%$ of the sample size were asked to fill out the survey instrument. The results of these respondents were used for survey instrument validation and reliability purpose. The value of cron back alpha for these responses was 0.836 which as per the multivariate data analysis book, [10] value of cron back alpha ranges between 0.75 to 0.93 is appropriate; [4] if cron back alpha is higher than 0.70 , the constructs used in the study are reliable.

\section{E. Robustness Analysis}

Since the value of the Corn back alpha for the instrument received is greater than 0.70, we consider the survey instrument to be reliable and proceed further to get responses from the remaining sample size of the study. Refer Table II for Corn back alpha test results.

\section{F. Summary}

This section is the way to drawing closer the previously mentioned research on finding the effect of sending of Scrum management System on hierarchical execution of movements studios in Pakistan. This part unmistakably distinguishes the populace for the exploration and dependent on that example size were determined, explaining the extent of the investigation. This section likewise explains on information gathering systems and methods, displaying diverse factual models and investigations to be utilized for assessing the said speculation. Approval of the instrument is likewise done in this stage.

TABLE. I. SCALES OF THE STUDY

\begin{tabular}{|c|c|c|}
\hline No. & Variable & Items / Statements \\
\hline 1. & $\begin{array}{l}\text { Deployment of } \\
\text { Scrum } \\
\text { management } \\
\text { System }\end{array}$ & $\begin{array}{l}\text { Q1. Scrum management System will help me in } \\
\text { my work. } \\
\text { Q2. Scrum management System will increase my } \\
\text { performance by providing correct information. } \\
\text { Q3. Scrum management System will help me in } \\
\text { decision making by providing information on time. } \\
\text { Q4. A software work is better than manual work or } \\
\text { verbal work. } \\
\text { Q5. Scrum management System allows } \\
\text { information in the sort of reports and screens to the } \\
\text { manager and many business professionals. } \\
\text { Q6. Scrum management System set a link to } \\
\text { communication, making activities and } \\
\text { responsibilities possible for administration and } \\
\text { managers. }\end{array}$ \\
\hline 2. & $\begin{array}{l}\text { Animation } \\
\text { Studios } \\
\text { Performance }\end{array}$ & $\begin{array}{l}\text { Q7. Scrum management System will have an } \\
\text { impact on the function, performance, and } \\
\text { productivity of the organization. } \\
\text { Q8. The monitoring of performance can be easily } \\
\text { measured with the help of Scrum management } \\
\text { System. } \\
\text { Q9. Scrum management System will help all } \\
\text { departments in Animation Studio of Pakistan to } \\
\text { perform effectively. } \\
\text { Q10. There can be a big role of Scrum } \\
\text { management System in an animation studio's } \\
\text { performance. }\end{array}$ \\
\hline
\end{tabular}


TABLE. II. RELIABILITY ANALYSIS

\begin{tabular}{|l|l|}
\hline Reliability Statistics & No. of Items \\
\hline Cron Back Alpha & 10 \\
\hline .762 & \\
\hline
\end{tabular}

\section{DISCUSSION}

Past section of this study featured populace for this exploration, test size and information gathering method that have been received. This part gives a spellbinding investigation of the information gathered through surveys and performed examination with relapse strategy to see results of the outcomes dependent on the hypothetical model and speculation created in going before sections. Further, it likewise give dependability investigation of the instrument that is utilized for gathering the information. This part additionally features discoveries of the Linear relapse test for finding the effect of the autonomous variable on the needy variable and dependent on these outcomes; basic investigation over the outcomes accomplished has been performed relating them with look into targets, inquire about questions and suggesting extension for future examines.

\section{A. Respondent Profile}

The respondent for this study has been selected from different organizations currently working in Animation Studio Industry, their profile is mentioned below indicating a number of male \& female respondents.

Fig. 2 indicates that out of 52 respondents, 32 respondents i.e. $62 \%$ of the sample population were male while 20 respondents i.e. $38 \%$ of the sample population were female. All (52 respondents) valuable responses have been taken into account for conducting this research (Table III).

\section{B. Descriptive Statistical Analysis}

Descriptive statistics are computed in order to assess the statistical properties of the research variable/constructs. Descriptive statistical analysis is presented in Table IV.

TABLE. III. RESPONDENT GENDER COUNT

\begin{tabular}{|l|l|l|}
\hline Gender & Count & \\
\hline Female & 20 & \\
\hline Male & 32 & \\
\hline Total & 52 & \\
\hline
\end{tabular}

\section{Sample of the Population}

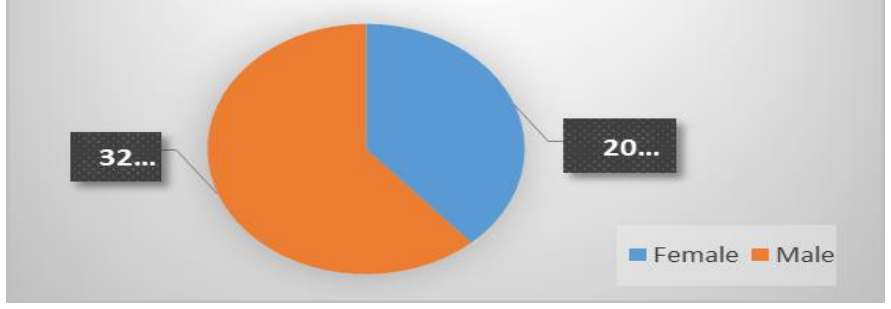

Fig. 2. Graphical Representation of Respondent Gender Count.
TABLE. IV. DESCRIPTIVE StatisticAl ANALYSIS

\begin{tabular}{|l|l|l|l|}
\hline \multirow{2}{*}{ Variables } & $\mathrm{N}$ & Mean & Std. Deviation \\
\cline { 2 - 4 } & Statistic & Statistic & Statistic \\
\hline $\begin{array}{l}\text { Deployment_Scrum } \\
\text { management System }\end{array}$ & 52 & 4.3017 & .46307 \\
\hline Performance_Increase & 52 & 4.0433 & .49190 \\
\hline
\end{tabular}

The aforementioned Table IV shows descriptive statistics of independent and dependent variables with their responses. The sample size of the respondent were 52 and there is no missing data in all the construct responses. Deployment of scrum management system has Mean $=4.30$ and Standard deviation $\mathrm{SD}=.46307$ while Performance Increase has Mean=4.04 with Standard Deviation SD=.49190.

\section{Reliability of the Constructs}

In order to examine the reliability of the constructs, the Cornbach alpha values are calculated and stated in Table V.

The aforementioned Table $\mathrm{V}$ show that reliability within the construct of Deployment of scrum management system (a $=0.804)$ is the highest followed by Performance Increase $(a=$ 0.728). Since both the values of Cornbach alpha is higher than 0.70 , therefore, it is safe to assume that the constructs used in this study are reliable [2] [3].

\section{Regression Analysis}

Regression is a statistical method used for analyzing the nature of the relationship between variables. The analysis includes what type of impact exist between variables; positive or negative linear or non-linear. The impact of the Deployment of Scrum management System on Organizational Performance has been examined through regression analysis. The regression results are summarized in Table VI.

Results of Table VI indicate that the Deployment of Scrum management System has a significant positive impact on Organizational Performance with $(\mathrm{B}=0.533, \mathrm{p}<0.05)$. The coefficient of the predictor variable is statistically significant at confidence interval $95 \%$.

TABLE. V. RELIABILITY ANALYSIS

\begin{tabular}{|l|l|l|l|}
\hline Variables & Mean & Std. Deviation & Cornbach's Alpha \\
\hline $\begin{array}{l}\text { Deployment_scrum } \\
\text { management system }\end{array}$ & 4.3017 & .46307 & 0.804 \\
\hline Performance_Increase & 4.0433 & .49190 & 0.728 \\
\hline
\end{tabular}

TABLE. VI. REGRESSION RESULTS (COEFFICIENTS) DEPENDENT VARIABLE: PERFORMANCE_INCREASE

\begin{tabular}{|l|l|l|l|l|l|}
\hline \multirow{2}{*}{ Model } & \multicolumn{2}{|l|}{$\begin{array}{l}\text { Unstandardized } \\
\text { Coefficients }\end{array}$} & $\begin{array}{l}\text { Std. } \\
\text { Coefficients }\end{array}$ & \multirow{2}{*}{$\mathrm{t}$} & Sig. \\
\cline { 2 - 6 } & $\mathrm{B}$ & Std. Error & Beta & & \\
\hline (Constant) & 1.752 & .562 & & 3.115 & 0.003 \\
\hline $\begin{array}{l}\text { Deployment_- } \\
\text { Scrum } \\
\text { management } \\
\text { System }\end{array}$ & .533 & .130 & .502 & 4.099 & .000 \\
\hline
\end{tabular}


TABLE. VII. REGRESSION RESULTS (MODEL SUMMARY)

\begin{tabular}{|l|l|l|l|l|}
\hline Model & $\mathrm{R}$ & R Square & $\begin{array}{l}\text { Adjusted } \mathrm{R} \\
\text { Square }\end{array}$ & $\begin{array}{l}\text { Std. The error of the } \\
\text { Estimate }\end{array}$ \\
\hline 1 & $.502^{\mathrm{a}}$ & .252 & .237 & .42980 \\
\hline
\end{tabular}

To answer the aforementioned RQ1, the hypothesis was developed. Regression results suggest that the Deployment of scrum management system has a positive and statistically significant impact on organizational performance with Beta Value $=0.533, p=0.000$ which is less than 0.05 ; therefore null hypothesis is rejected and Alternative (claimed) hypothesis is accepted.

\section{CONCLUSION}

Information system arrange information according to client prerequisites consequently. Associations live and inhale on monetary information. As people, we utilize and exchange it to look after request. So the board data frameworks give us how we can utilize PC produced scientific models to empower advancements in information the executives and empower individuals to work adequately. It is a territory of between disciplinary research between business science and software engineering.

While working with enormous information or distributed computing as a space, programming like TACTIC enables huge gatherings of artists to envision new foundations while keeping up a smooth work process. The product permits the centralization of innovation that aids basic leadership, arranging and laying out procedures as opposed to film studios attempting to center a great deal of their interests in IT all alone. It is a direct result of a straightforwardness of the consistently changing pipeline through and through that upper administration can control the creation team towards accomplishing higher economies of scale.

Open source software is code that is available to the public, free of charge. Developers can inspect, make changes and constantly monitor the application's performance. This allows users trained in both Macintosh and Windows operating systems to communicate seamlessly without needing to buy new machines or hardware. This appears cost effective but requires the services of trained IT professionals to either be added to the payroll or outsourced, as well as provide the incentive to constantly undergo additional training.

A key test that ought to be tended to is thinking of a procedure to manage the lofty expectation to learn and adapt while presenting another strategy for attempting to both administration and the IT division of a film organization. With regards to dynamic situations, programming prologue to an Adhoc procedure changes the hierarchical culture. Some adjust rapidly, while others will set aside somewhat more effort to make up for lost time with their companions. The business impacts how we assess the innovation speculation also.

\section{A. Summary of Main Findings}

Numerous associations are organized dependent on practical territories. This is frequently reflected in an authoritative outline. Ordinarily useful zones incorporate funds, HR, advertising, fabricating, and so forth. In this situation, we have seen that the execution of the TACTIC the executives data framework in a film organization enables upper administration to incorporate liveliness data from different sources, give simple access to execution data in abridged structure, think about notable and current action and aid aggregate investigation with simple to-utilize devices.

\section{B. Limitations of the Study}

The animation business is extremely huge and furthermore called the cash multiplier industry. This specific examination will concentrate on the Animation Studios of Pakistan. The all out populace is the staff working in Animations Studios in Pakistan, incorporates generation and non-creation (administrative and authoritative) staff. The constraint of the investigation is that we have not very many movement studios in Pakistan. The all out number of animation studios of Pakistan is 10 with around 1000 generation and around 200 non-creation staff. The assortment of information will be done through a poll and from creation staff just, cooking the catering both genders staff on an accommodation inspecting premise. The present investigation has one autonomous variable. Scrum management System Deployment in Animation Studio. While one ward variable is the authoritative execution of liveliness studios. Numerous elements influence Animation Studios Performance. In any case, this investigation is concentrating just on one variable that is thought to be very sound for the movement business of Pakistan. The extent of this examination won't be constrained to this exploration, yet it could be conveyed forward with a similar variable in different areas of Asia and the remainder of the world.

\section{REFERENCES}

[1] ARAGON-CORREA J and SHARMA S (2003) A contingent resourcebased view of proactive corporate environmental strategy. Academy of Management Review 28(1), 71-88.

[2] Isabella Mayer Firm Qualitative Research with A Focus On Qualitative Data Analysis . International Journal of Sales, Retailing and Marketing.

[3] Nancy Leech, George Arthur Morgan, Karen Barrett SPSS for Intermediate Statistics: Use and Interpretation. Isbn: 978-184872-999-5 January 2015.

[4] Muhammad Nasir Khan, Dr. Tariq Jalees Human Resource Management Practices and Employee Performance in Pakistan. Vol 12, No 2 (2017).

[5] BHARADWAJ A (2000) A resource-based perspective on information technology capability and firm performance: an empirical investigation. MIS Quarterly 24(1), 169-196.

[6] BHATT G and GROVER V (2005) Types of information technology capabilities and their role in competitive advantage: an empirical study. Journal of Management Information Systems 22(2), 253-277.

[7] BURTON-JONES, A., \& GALLIVAN, M. J. (2007). Toward a deeper understanding of system usage in organizations: a multilevel perspective. MIS Quarterly 31(4), 657-679.

[8] DEHNING B and RICHARDSON VJ (2002) Returns on investments in information technology: a research synthesis. Journal of Information Systems 16(1), 7-30.

[9] DEVARAJ, S., \& KOHLI, R. (2003). Performance impacts of information technology: is actual usage the missing link Management Science, 49(3), 273-289.

[10] Josenh F. Hair Jr. William C. Black. Barrv J. Babin Rolnh E. Anderson. Multivariate Data Analysis Hair Black Babin Anderson 7th edition. 
[11] GABLE, G. G., SEDERA, D., \& TAIZAN CHAN (2008). Reconceptualizing Information System Success: The IS-Impact Measurement Model. Journal of the Association for Information Systems, 9(7), 1-32.

[12] GRANT R (1991) The resource-based theory of competitive advantage. California Management Review 33(3), 114-135.

[13] HENDRICKS, K. B., SINGHAL, V. R., \& STRATMAN, J. K. (2007) The impact of enterprise systems on corporate performance: A study of ERP, SCM, and CRM system implementations. Journal of Operations Management, 25(1), 65-82.

[14] IGBARIA, M., \& TAN, M. (1997). The consequences of information technology acceptance on subsequent individual performance. Information \& Management, 32(3), 113-121.

[15] KENNETH LAUDON, JANE P.LAUDON (2003). Essentials of Management Information System. 5th edition. Prentice-Hall, Inc, New Jersey.
[16] MELVILLE, N., KRAEMER, K., \& GURBAXANI, V. (2004). Review: Information technology and organizational performance: An integrative model of IT business value. MIS Quarterly, 28(2), 283-322.

[17] PORTER M (1985) Competitive Advantage. Free Press, New York.

[18] STOEL D and MUHANNA W (2009) IT capabilities and firm performance: a contingency analysis of the role of industry and IT capability type. Information \& Management 46(3), 181-189.

[19] WADE M and HULLAND J (2004) Review: The resource-based view and information systems research: review, extension, and suggestions for future research. MIS Quarterly 28(1), 107-142.

[20] BARNEY J (1991) Firm resources and sustained competitive advantage.

[21] BARRY, S. (1998):Introduction to Computer Information System. New York, Rinelart and Winston. 